Supporting information

\title{
Interfacial Synthesis of Cellulose-derived Solvent- responsive Nanoparticles via Schiff base Reaction
}

Hua Zhang ${ }^{\dagger}$, Peiwen Liu ${ }^{\dagger}$, Xinwen Peng ${ }^{\ddagger}$, Shuiliang Chen $\ddagger$, Kai Zhang *广

† Wood Technology and Wood Chemistry, Georg-August-Universität Göttingen,

Büsgenweg 4, D-37077 Göttingen, Germany.

$\ddagger$ College of Chemistry and Chemical Engineering, Jiangxi Normal University, Nanchang, Jiangxi 330022, PR China.

* Corresponding author. Email: kai.zhang@uni-goettingen.de 
Table S1. Summary of parameters of as-prepared DANPs determined by element analysis

\begin{tabular}{clcccc}
\hline \multirow{2}{*}{$\begin{array}{c}\text { Reaction } \\
\text { Interface }\end{array}$} & Samples & \multicolumn{3}{c}{ Element contents (wt. \%) } & \multirow{2}{*}{$\begin{array}{c}\text { Degree of } \\
\text { substitution }\end{array}$} \\
\cline { 2 - 5 } & & $\mathrm{C}$ & $\mathrm{N}$ & $\mathrm{H}$ & \\
\hline \multirow{3}{*}{$\begin{array}{c}\text { Droplet } \\
\text { interface }\end{array}$} & DANPs-0.25 & 56.97 & 3.27 & 5.89 & $0.31 \pm 0.002$ \\
\cline { 2 - 6 } & DANPs-0.5 & 52.04 & 3.64 & 5.70 & $0.56 \pm 0.002$ \\
\cline { 2 - 6 } & DANPs-1 & 54.85 & 4.55 & 5.62 & $0.74 \pm 0.004$ \\
\cline { 2 - 6 } & DANPs-4 & 60.57 & 6.44 & 5.86 & $1.21 \pm 0.005$ \\
\hline \multirow{3}{*}{$\begin{array}{c}\text { Planar } \\
\text { interface }\end{array}$} & DANPs-0.25 & 56.38 & 3.18 & 4.97 & $0.28 \pm 0.003$ \\
\cline { 2 - 5 } & DANPs-0.5 & 55.70 & 4.15 & 5.14 & $0.62 \pm 0.002$ \\
\cline { 2 - 5 } & DANPs-1 & 54.95 & 4.63 & 5.54 & $0.76 \pm 0.007$ \\
\cline { 2 - 5 } & DANPs-4 & 58.94 & 6.49 & 6.09 & $1.30 \pm 0.005$ \\
\hline
\end{tabular}




\section{Evaluation of pH value and ionic conductivity in aqueous phase}

The experiment containing the biphasic system was carried out without DAC under otherwise equal conditions as in the interfacial Schiff base reaction. Certain amounts of aniline dissolved in $10 \mathrm{~mL}$ of toluene was prepared as organic phase and $10 \mathrm{~mL}$ of pure DI water was chosen as water phase.

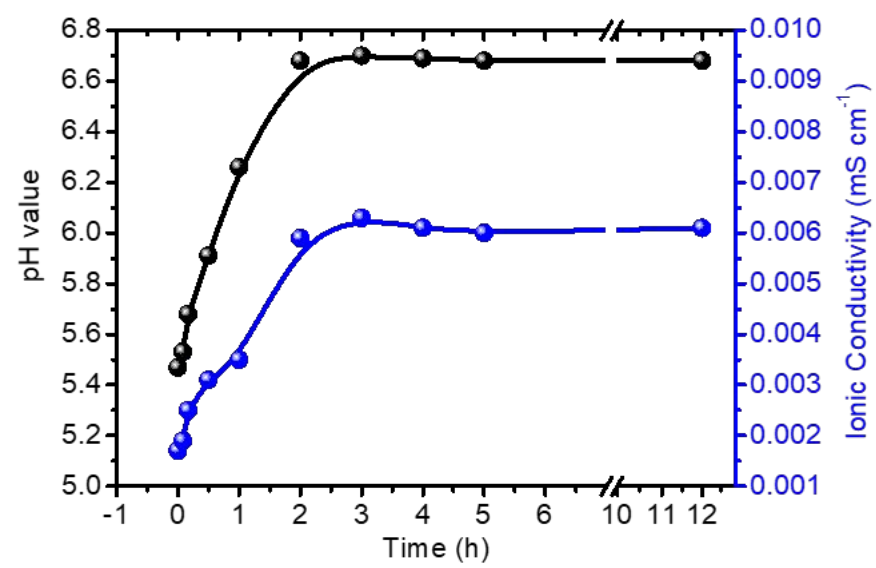

Figure S1. Analysis of $\mathrm{pH}$ value and ionic conductivity in aqueous phase to study the diffusion of aniline molecules from organic phase to water phase.

The $\mathrm{pH}$ value of pure DI water was measured to be $5.47 \pm 0.1$ and the conductivity was $0.0017 \pm$ $0.0001 \mathrm{mS} \mathrm{cm}^{-1}$. The increase of $\mathrm{pH}$ value and ionic conductivity in water phase was caused by the diffusion of aniline molecules in aqueous phase from toluene phase. Due to its limited solubility in water, the $\mathrm{pH}$ value of aqueous phase was stable at $6.68 \pm 0.1$ and the conductivity was finally maintained at $0.0060 \pm 0.0002 \mathrm{mS} \mathrm{cm}^{-1}$ after $3 \mathrm{~h}$ without further changes. These results indicate a slowly diffusion process of aniline in water phase, as well the limited solubility. Combined with the results of time-dependent formation of DANPs, thus we proposed that the Schiff base reaction was mainly take place at the liquid/liquid interface, not in the aqueous phase. 


\section{Examination of pH-responsiveness behaviors of DANPs}

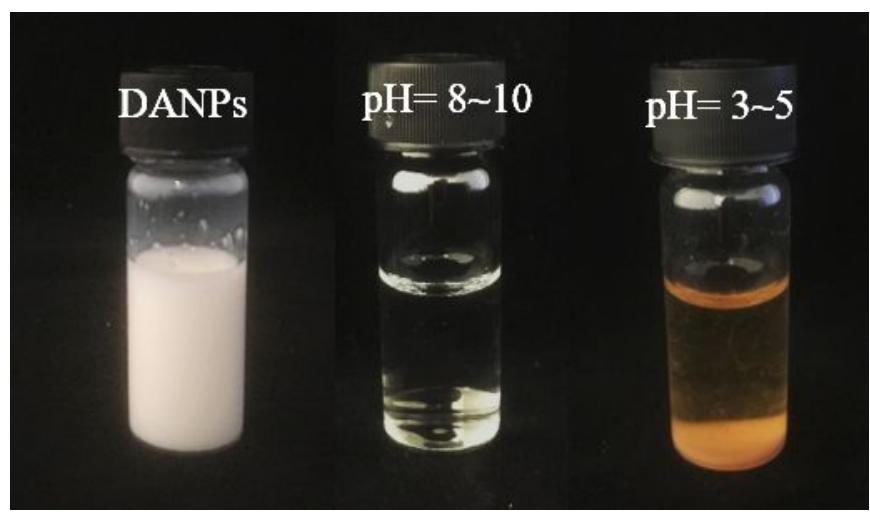

Figure S2. Digital photos of obtained DANPs and their stability under acidic or basic conditions.

As seen, the obtained DANPs via Schiff-base coupling displayed a thoroughly opalescent suspension. It is well known that Schiff base bonds are pH-responsive: they are stable in an aqueous alkaline solution of high $\mathrm{pH}$ values and easy to be cleaved under acidic conditions of low $\mathrm{pH}$ values. However, by adjusting its environment to achieve a basic $(\mathrm{pH}=8-10)$ or acidic $(\mathrm{pH}=3-5)$ condition, the aqueous DANPs solution quickly changed to a transparent or brownish-yellow solution. This phenomenon differs from the commonly Schiff base bonds, which may be attributed to the side-reactions and the rapid degradation of DAC backbone. 
Examination of the tolerant and stabilization dispersed capacity of DANPs
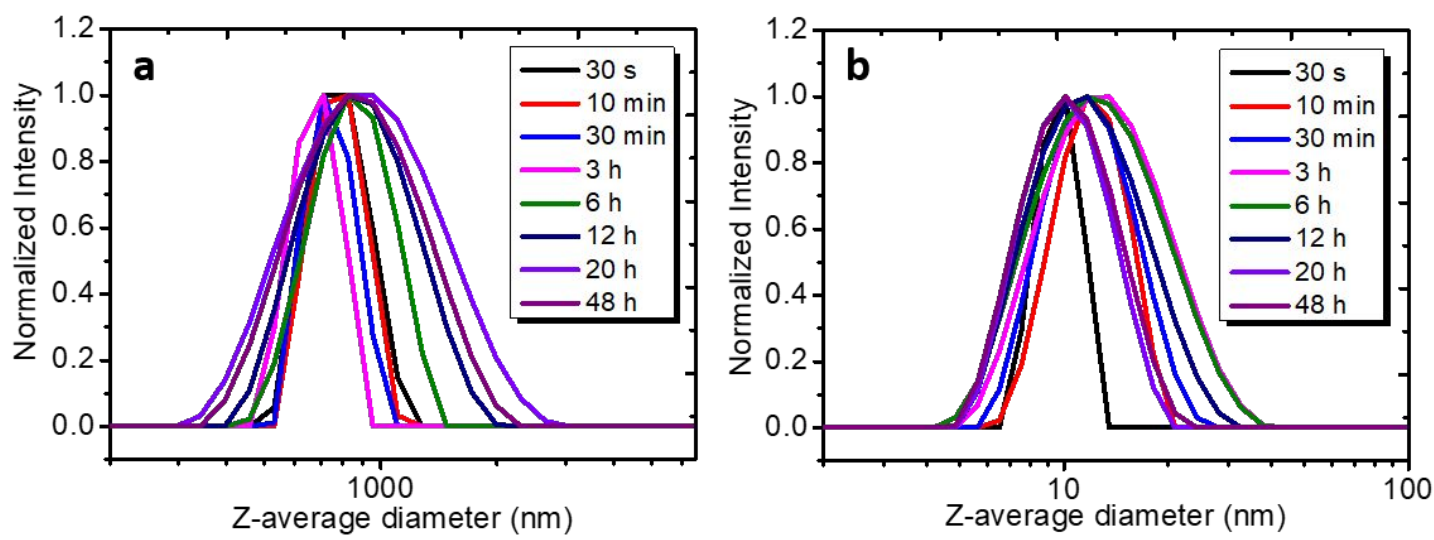

C

\begin{tabular}{lcccc}
\hline \multirow{2}{*}{ Reaction Time } & \multicolumn{2}{c}{ Ethanol } & \multicolumn{2}{c}{ THF } \\
\cline { 2 - 5 } & \multicolumn{1}{c}{ Diameter $(\mathrm{nm})$} & PDI & Diameter $(\mathrm{nm})$ & PDI \\
\hline $5 \mathrm{~min}$ & $800 \pm 4$ & $0.09 \pm 0.04$ & $13.6 \pm 0.5$ & $0.26 \pm 0.02$ \\
$10 \mathrm{~min}$ & $803 \pm 3$ & $0.07 \pm 0.02$ & $13.0 \pm 0.3$ & $0.21 \pm 0.03$ \\
$30 \mathrm{~min}$ & $801 \pm 4$ & $0.06 \pm 0.03$ & $12.8 \pm 0.3$ & $0.24 \pm 0.04$ \\
$3 \mathrm{~h}$ & $805 \pm 3$ & $0.07 \pm 0.02$ & $12.9 \pm 0.5$ & $0.20 \pm 0.05$ \\
$6 \mathrm{~h}$ & $808 \pm 2$ & $0.08 \pm 0.03$ & $12.6 \pm 0.4$ & $0.23 \pm 0.02$ \\
$12 \mathrm{~h}$ & $810 \pm 4$ & $0.10 \pm 0.05$ & $12.3 \pm 0.2$ & $0.24 \pm 0.03$ \\
$20 \mathrm{~h}$ & $804 \pm 2$ & $0.10 \pm 0.04$ & $12.5 \pm 0.5$ & $0.21 \pm 0.04$ \\
$48 \mathrm{~h}$ & $806 \pm 3$ & $0.08 \pm 0.03$ & $12.5 \pm 0.3$ & $0.23 \pm 0.02$ \\
\hline
\end{tabular}

Figure S3. DLS curves of obtained DANPs-0.5 at various reaction times in (a) ethanol and (b) THF dispersant. (c) The corresponding Z-average diameters and PDI data. 